\title{
Operational Solutions That Help Voting Work for Everyone
}

\author{
Jim Terry, Kaylan Dunlap, Steve Flickinger, \\ and Dan Woosley
}

\begin{abstract}
This case study presents the election monitoring best practices that Evan Terry Associates (ETA) has observed and developed to be shared with polling locations across the country. There are numerous details to observe and many distractions that can divert Americans with Disabilities Act (ADA) monitors and poll workers during an actual election, especially relating to little or lesser known issues of accessibility for voters with disabilities. The best practices presented can help to consolidate, expedite, and focus accessibility monitors throughout the country as it relates to barriers to accessibility issues at polling places.
\end{abstract}

Keywords Accessibility $\bullet$ Americans with Disabilities Act $\bullet$ Polling locations $\bullet$ Poll workers

J. Terry $(\bowtie) \bullet$ K. Dunlap $\bullet S$. Flickinger $\bullet$ D. Woosley

Evan Terry Associates, LLC., Birmingham, AL, USA

e-mail: jterry@evanterry.com

(C) The Author(s) 2019

M. Brown et al. (eds.), The Future of Election Administration, Elections, Voting, Technology, https://doi.org/10.1007/978-3-030-18541-1_28 
Without question, the key player on Election Day is the poll site coordinator, a role that can have many different names. Each polling place is assigned a leader (or leaders) who have full authority to conduct polling efforts at that site during an election event. The role of poll site coordinator is to serve as captain of the ship, so to speak. This individual takes on the daunting duty and responsibility to make sure that voting is a positive experience for voters and poll workers alike and it requires the individual to undertake a considerable amount of training to acquire all of the requisite knowledge and skills to perform during a grueling 12- to 15-hour Election Day.

Although the poll site coordinator's individual duties and responsibilities are numerous, varied, and can certainly be intimidating, Evan Terry Associates (ETA) has observed that, in many election districts, the area of least focus has been a thorough understanding across the election office of the accessibility needs of those voters with disabilities. ADA (Americans with Disabilities Act) requirements can seem to be overwhelming in quantity and scope. Historically, poll site coordinators have been ill-equipped to address in any meaningful way a physical barrier to accessibility at a polling place because they have no actual authority outside of the immediate voting process and procedure.

In order to ensure that no citizen is denied any protected right due to a disability, ETA has determined from its observations and experience that there are three key areas on which every board of elections should focus as it relates to physical accessibility at polling places. These key areas center on (1) practical ADA-related poll site coordinator training, (2) ensuring better ADA training for polling staff, and (3) providing knowledgeable on-site ADA expertise and/or assistance. Many boards of elections have vigorously and productively addressed all three of these key issues during the past several years, which have greatly improved access throughout their jurisdictions.

One important question revolves around whether the results of polling place accessibility surveys are tied to the poll workers' training. In other words, how do poll workers know what barriers to accessibility exist at their site. The absence of that knowledge is a formula for failure to provide an accessible polling place. Poll worker training courses are rife with policies, procedures, and laws pertaining to the actual ballots and voting, and rightly so. The structure of the training is generally very well thought out, organized, managed, and very inclusive in everything related to polling policies and procedures during an election period, 
including voter registration and election administration. Accessibility is one more very important topic that must be covered in that training. ETA's experience indicates that the most effective approach to accessibility training is the positive approach that the jurisdiction wants to make the voting experience easy for everybody, including people with disabilities. While it is certainly reasonable to mention the fact that access to voting is a civil rights requirement, it may be best not just to focus on the ever-increasing number of ADA lawsuits that require it. The term "disability friendly" is a great one to put the concept into a proper perspective.

Training sessions are generally taught by highly qualified trainers-typically those who have served in various poll worker roles for several years. Unfortunately, often there is little to no content that includes a practical and nuanced focus on disability awareness, including the state of accessibility at the very site to which they are assigned. Of course, this limitation begs the question: what efforts have been exercised to provide a full accessibility survey of the facilities in the election district, including transition and action plans to ameliorate whatever is required to make the site fully accessible? If it hasn't been done, it should be.

A frequent observation by ETA during poll worker training, especially when attempts are made to share accessibility theories and requirements, is that demonstrations and explanations can be entirely wrong or misleading. Complex standards such as door maneuvering clearances, turning spaces, and protruding objects have been incorrectly demonstrated by the trainers of accessibility requirements due to their lack of knowledge of the ADA standards. These examples, which are critically important to voter entry, access, and exit, are just a few of several nuanced topics of the ADA requirements that are sometimes discussed during training sessions. Because they are little known by the consuming public, including the teachers of the polling process, confusion often ensues.

One of the ongoing efforts by ETA architectural accessibility specialists has been to review election cycle documents, which include existing training materials, resulting in composing and editing accessibility dialogue into the various poll worker training manuals, such as those provided for General Poll Workers, Accessibility Clerks, Interpreters, Ballot Marking Device Operators, and Poll Site Coordinators. The contents of training presentations, guides, videos, and tests for each of the specific roles also need to be coordinated with the manuals so policies and procedures are consistent. Election officials are encouraged to have ADA specialists perform this function annually, or whenever the content of training materials change. 
One specific topic that is sometimes absent from these documents is the lack of discussion of the legal requirements of the Americans with Disabilities Act - the ADA. Existing documents usually feature the 2002 Help America Vote Act (HAVA) which mandates that all voters be provided the opportunity to vote privately and independently. However, there is usually little or no discussion of the civil rights law-the ADA-that prohibits discrimination against individuals with disabilities in all areas of public life, including access to all public and private places that are open to the general public, including those used as polling places.

It is important to include the ADA's intent in any "Legal Notice" section of every training manual. Likewise, including a segment on disability awareness will benefit poll workers, and possibly an "ADA/Accessibility Supplement" to accompany the various manuals and materials. The addition of content to enhance and explain the meaning and understanding of various accessibility terms and concepts, explanations of how each accessibility feature at the polling place is supposed to work, descriptions of how to maintain the accessible features, and explanations of how to communicate effectively with people with a variety of disabilities will serve to improve poll worker performance during the course of the election day.

One of the results of ETA's polling place surveys for the City of New York was the development of poll worker training videos that are used in training poll workers and others associated with polling place setup and operation. This type of visual instruction is beneficial to poll workers' understanding of the challenges associated with voting by people with disabilities and how they can help to eliminate or minimize those problems. The videos demonstrate the most common barriers to accessibility that poll workers are most likely to encounter on election day and specifically the types of barriers that they can correct. Most of these training videos each focus on the particular poll worker positions used in the City, and include the following topics: ${ }^{1}$

\section{Communications and Etiquette (Parts 1 and 2)}

[For all poll workers] Describes how to ensure that each and every person with a disability has an opportunity to vote in an integrated environment that is both dignified and convenient; demonstrates communication with real people with a broad variety of disabilities that affect communications;

\footnotetext{
${ }^{1}$ These videos can be readily viewed at www.boevideos.com.
} 
describes etiquette for working with people with disabilities; demonstrates scenarios that might occur on election day and how they can be resolved.

\section{Accessibility Clerk Responsibilities}

[For the Accessibility Clerk] Accessibility Clerks are poll workers on the front lines who interact with voters and ensure that every voter has the physical opportunity to cast their vote at a polling place in an environment that is safe, dignified, and convenient. This video features the duties of the Accessibility Clerk, which include posting signage, staffing entrance and interior doors and elevators, and providing other assistance to all voters.

\section{Verifying Voting Equipment Setup}

[For the Site Coordinator and Accessibility Clerk] This video shows how to inspect and measure polling places to verify that required door maneuvering clearances, accessible routes, and clear floor spaces at equipment are being maintained. It describes to Site Coordinators what to look for when verifying the voting equipment setup and how to correct any problems that are found, including making certain that all the tables and voting equipment will properly fit into the voting area. It describes how to use their drawings that show exactly where everything needs to be placed with dimensions, and it describes how to read and interpret those drawings.

\section{SIGNAGE}

[For the Site Coordinator and Accessibility Clerk] This video describes the use and placement of various accessibility notification, directional, and location signs used on election day, and it describes where and how to secure signs and the requirement to periodically check them.

\section{Ballot Marking Device (BMD) Accessible Features} AND OPERATION

[For the Site Coordinator and Ballot Marking Device Inspector/Operator] This video describes how to set up and verify that all additional accessories are on hand and it demonstrates how to use each of the accessible features of the Ballot Marking Device for people who have various types of disabilities. 
Produced for viewing in training classes and for review by individual poll workers whenever they like on their cell phones, election day monitoring has shown dramatic improvements in accessibility for voters with disabilities after poll workers have watched these videos. The use of accessibility specialists as Election Day ADA monitors or observers can also be very beneficial. The intended purpose of such monitoring is to help the Board of Elections meet its ADA compliance obligations by verifying the ongoing compliance of temporary equipment (portable ramps, curb ramps, cones, directional signage, the use of mats), interior configurations of polling equipment, clear floor spaces, and accessible routes. Monitors can also help poll site workers to better understand the requirements of the Department of Justice ADA Checklist for Polling Places as it applies to existing barriers observed in that jurisdiction's poll sites; and how to facilitate effective program access in existing polling places. ${ }^{2}$

Election officials can improve Election Day ADA compliance by focusing on training for poll site leaders that includes the practical conditions of the ADA requirements for the sites in the jurisdiction. They can also focus on training that emphasizes a message of service to all voters, rather than focusing on lawsuits. Last, election officials can seek out ways to ensure better ADA training for polling staff and providing knowledgeable on-site ADA expertise and/or assistance.

${ }^{2}$ For ADA checklist see https://www.ada.gov/votingck.htm. 
Open Access This chapter is licensed under the terms of the Creative Commons Attribution 4.0 International License (http://creativecommons.org/licenses/ by $/ 4.0 /$ ), which permits use, sharing, adaptation, distribution and reproduction in any medium or format, as long as you give appropriate credit to the original author(s) and the source, provide a link to the Creative Commons licence and indicate if changes were made.

The images or other third party material in this chapter are included in the chapter's Creative Commons licence, unless indicated otherwise in a credit line to the material. If material is not included in the chapter's Creative Commons licence and your intended use is not permitted by statutory regulation or exceeds the permitted use, you will need to obtain permission directly from the copyright holder. 